\title{
地球内部の異方性と $\mathrm{S}$ 波のスプリッティング
}

\author{
カーネギー研究所, DTM* 金 嶋 聰
}

\section{Shear-wave Splitting Induced by Seismic Anisotropy in the Earth}

\author{
Satoshi Kaneshima \\ Carnegie Institution of Washington, Department of Terrestrial Magnetism, 5241, \\ Broad Branch Road, N. W. Washington, D. C. 20015. U.S.A. \\ (Received November 4, 1989; Accepted December 5, 1990)
}

\begin{abstract}
It is believed that seismic anisotropy represents dynamics of the Earth's interior, directly reflecting either instantaneous stress, cumulative strain, or deformation of in-situ rocks. A shear wave passing through an anisotropic elastic medium splits into two orthgonally polarized quasi-shear waves with different propagation speeds. This phenomenon is called shear wave splitting, and is useful to understand the Earth's anisotropic fabric, with potential advantages as high lateral resolving power and relatively low sensitivity to seismic wave velocity heterogeneities. During the past decade, a variety of anisotropy-induced shear wave splitting has been observed in many different fields of seismology, indicating that anisotropy is an ubiquitous feature in the Earth's crust and upper mantle. In this review I summarize recent observations of shear wave splitting, with special emphases on their geophysical implications. I also discuss several problems concerned with shear wave splitting analyses, which are expected to be solved in the near future.
\end{abstract}

Key words: Seismic anisotropy, Shear wave splitting, Upper mantle, Upper crust.

\section{§1.はじめに一地球科学, 地震学, 地震波異方性} 固体地球科学の中で地震学が果たしてきた役割を簡単 にまとめると以下のようになろう。地震学者は, 地震波 の伝播距離と時間との関係, 波形, スペクトル等を調べ て地球内部の弾性波速度を推定した. 彼らが提出した地 球の地震波速度モデルは高温高圧での弾性波実験の結果 之対照されて, 人間の手の届かない地球深部にどんな物 質がいかなる状態で存在するかを推定可能にした。ささら に地震の発生機構の解明を通じて, 地球内部にどんな力 が㗢いているか，あるいはプレート間にどんな相対的運 動が起こっているかを明らかにし，プレートテクトニク スの確立に大きく貢献した.

地震学のデー夕を扱う際には，観測点や震源の配置及 び地震記象の質など主にデー夕上の制約から地球を等方 弾性体と近似する場合が多かった．地球内部の岩石組成 の複雑さを捨象して $\mathrm{P}$ 波と $\mathrm{S}$ 波の伝播速度及び密度と いうパラメタで表現し, 地球深部構造に関して他の分野

* 現在 $\overline{7} 113$ 東京都文京区弥生 2-11-16 東京大学理学部地球物理学教室
ではとても考えられない高い空間的解像度を達成した. 例えば近年, 実体波や表面波や自由振動などありとあら ゆる種類の弾性波を用いて行われている地震波速度構造 の研究は, 地球内部の三次元的な速度分布をも明らかに しつつあり，その結果は我々に間接的にではあるが地球 内部の温度分布と運動を知る手がかりを与えた。しか し，岩石を構成する鉱物結晶の多くは大きな弾性的異方 性を持つ事が知られており, 地球を等方的として扱う事 がどこまで妥当かは必ずしも明かでない，大きな領域を ならしてみれば様々な鉱物が様々な方向の結晶配列を持 つと考えると等方的物質の仮定はそれほど的はずれでは ないかむ知れない. しかし，地殼には場所により 1,000 $\mathrm{km}$ に及ぶ広い領域でほぼ一様な応力が働いてるし，プ レートの運動は地球内部の大規模な運動（マントル対 流）の存在を示唆している. 室内で行われる様々な実験 から, 地球内部に存在すると思われる岩石が変形や応力 を受けると弾性率は大きな異方性を示す事が分かってい るので，このようなダイナミックな地球内部では岩石が 広い領域で一様な異方性を帯びる可能性は高い，地震波 異方性は, 地球内部の岩石の変形や応力といったダイナ 
ミックな性質を推定する手がかりを与えてくれる. それ ばかりでなく, 弾性定数のより詳細な知識は地球内部の 岩石の鉱物組成や化学組成をより詳しく知る事にもつな がる.

近年の観測記録の質的向上により，地球内部の異方性 構造の研究が可能となった. 地球内部の異方性を示すと 思われる現象は以下に述べるごとく多様である.つま り, 地震波（P 波，表面波など）伝播速度の方位依存性 [Shimamura et al. (1983), TANimoto and Anderson (1984) 等].ラブ波とレイリー波の分散から推定される 速度構造の食い違い [DzIEWONSKI and ANDERSON (1981)]. S 波のスプリッティング. 自由振動モードの分 裂 [MochIZUKI (1986)] 等である.これらの中で「S 波 のスプリッティング (shear wave double refraction, shear wave birefringence, shear wave splitting)」は, 地球内部の異方性を研究する上でいくつかの大きな利点 を備えている. まず実体波に関わる現象であり, 長周期 の表面波の研究に比べて高い空間的解像度を持つ. ま た, 速度不均質構造に影響されにくいため直接的な異方 性の証拠となり得る。この現象の存在は, 理論的にあま た実験的にも古くから知られていたが，1980年代を通 じて様々なフィールドで観測され地球内部の異方性構造 を明らかにする重要な鍵となった。

本稿ではまず第 2 節で $\mathrm{S}$ 波のスプリッティングの概 略を述べ, つづく三節で地震学の諸分野での観測例, 特 に地款深部と上部マントルに関する諸研究を紹介し，そ れらの地球科学的意義について考察を加える. 最後に第 6 節でこの課題に関して今後解決が望まれる問題点を概 観する.

\section{§ 2. $\mathrm{S}$ 波のスプリッティング}

弾性率の異方性は, その弾性体を構成する鉱物の結晶 が特定の方向に選択的に配列（選択配向）したり，弾性 体内に存在する割れ目（クラック）が一定の方向に配列 する事によって生ずる [例えば竹下・唐戸(1989)]。 ま た，たとえ媒質自体は等方的でも差応力の働きにより弾 性波伝播に見かけの異方性が生じる.しかしこの差応力 の異方性に対する効果は, 鉱物やクラックに比べて小さ いと予想されている [DAHLEN (1972)].

地震波異方性に関連する現象は多様で, 数多くの理論 的研究が行われているが, ここでは $\mathrm{S}$ 波 (実体波) のス プリッティングについて簡単に説明するにとどめる [詳 しくは, Musgrave (1970), CRAMPIN (1981) 等を参照さ れたい].この現象は岩石顕微鏡と類似した原理に基づ く. 岩石顕微鏡は岩石を構成する諸鉱物を伝わる光が, 鉱物の屈折率の光学的異方性によって複屈折を起こす性

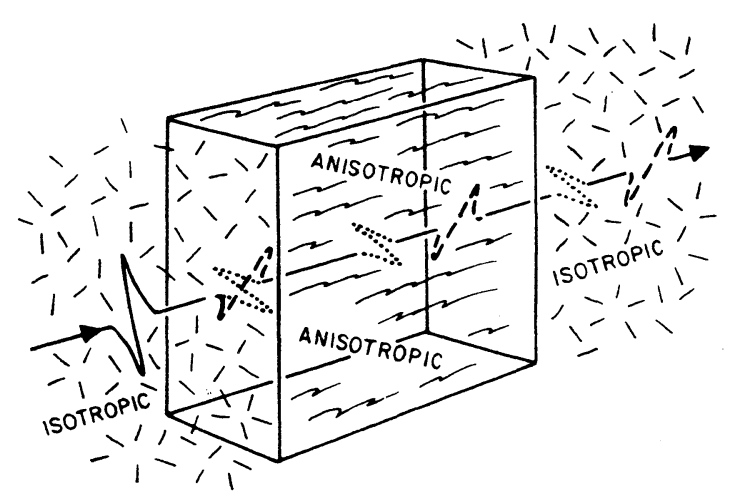

Fig. 1. Schematic figure of shear wave splitting. A shear wave travelling through an anisotropic medium splits into two orthogonally polarized (quasi-)shear waves with different propagation speeds [from CHRISTENSEN (1984)].

質を利用している [例えば，坪井 (1959)]．Ｓ波のスプ リッティングはこれと類似した弾性的な現象と考えてよ かろう.

一般的な異方性均質弾性媒質内の運動方程式（波動方 程式)は,

$$
\rho \partial^{2} u_{i} / \partial t^{2}=c_{i j k l} u_{k, l j}
$$

$u$ は変位, $c i j k l$ は弾性定数 $(i, j, k, l=1 \sim 3), \rho$ は密度 を表す.ここで平面波, $u_{i}=u_{0} p_{i} \exp [-i \omega(t-\boldsymbol{s} \cdot \boldsymbol{x})]$ の入 射を考える. $\omega, \boldsymbol{s}, \boldsymbol{x}, \boldsymbol{p}$ は, 角周波数, slowness ベクト ル, 位置ベクトル, 及び, 振動ベクトルを表す. slowness ベクトルは $\boldsymbol{s}=\boldsymbol{n} / v$ と表され, $\boldsymbol{n}$ は速度ベクトルの 方向, $v$ は速度の大きさを示す。この場合波動方程式は,

$\left(c_{i j k l} s_{j} s_{l}-\rho \delta_{i k}\right) p_{k}=0$

となり,これが有意な解を持つためには,

$$
\operatorname{det}\left(\rho v^{2} \delta_{i k}-c_{i j k l} n_{j} n_{l}\right)=0
$$

このように問題は固有值方程式に帰着し，伝播方向 $\boldsymbol{n}$ 対して三つの固有值が存在して, 各々が三つの異なる波 の $\rho v^{2}(1,2,3)$ を，また固有関数はそれらの波の振動べク トルを表す. $\boldsymbol{n}$ 方向の速度 $v$ を $v(\boldsymbol{n})$ とする. $v(\boldsymbol{n})$ は速度 曲面 (velocity surface) と呼ばれる閉曲面をなす。等方 媒質中では三つの速度曲面は全て同心球面となり, 位相 速度が方位に依存しないことを意味する。さらに波線 (n) に直交する振動べクトル $(\boldsymbol{p})$ を持つ二つの波は残り の一つよりあ小さい速度を持ちそれらの速度曲面は完全 に重なる（通常これらをまとめて S 波と呼び，S 波は縮 退しているという. S 波は純粋な剪断波である）[AKI and RICHARDS (1980)]. 残りの波は波線に平行な振動べ クトルを持ち P 波と呼ばれる.ところが一般の異方性媒 質に対しては三つの波の速度曲面はむはや球面ではなく 

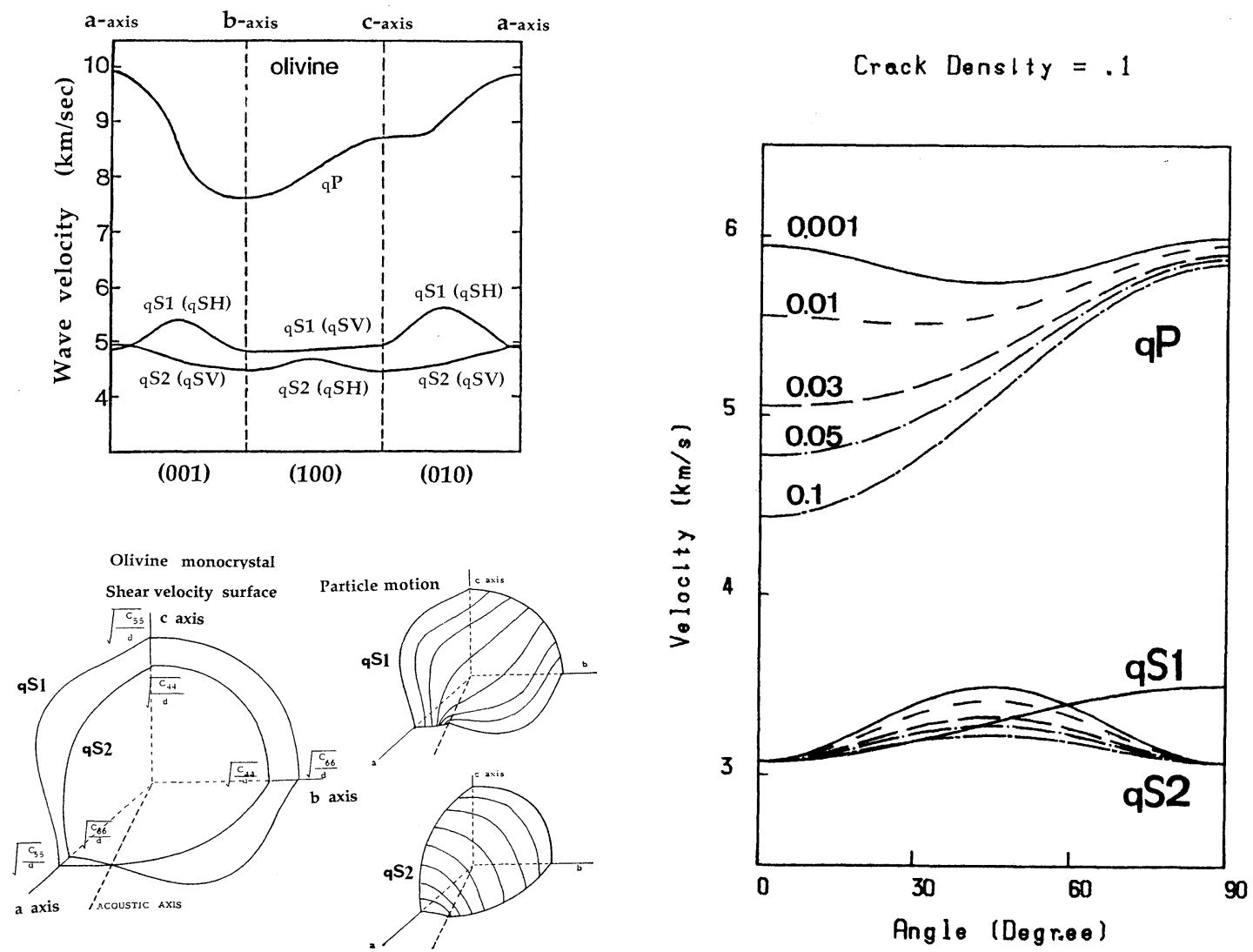

Fig. 2. (a:Left), Top: Variation of the quasi-P $(q \mathrm{P})$ and the two quasi-S $\left(q \mathrm{~S}_{1}, q \mathrm{~S}_{2}\right)$ body-wave phase velocities for propagation in the three $((001),(100)$, and (010)) orthogonal planes of symmetry of crystalline olivine. In each plane, $q \mathrm{~S}_{1}$ and $\mathrm{qS}_{2}$ correspond either to $q \mathrm{SH}$ or to $q \mathrm{SV}$, where $q \mathrm{SH}$ and $q \mathrm{SV}$ represent the shear waves polarized nearly parallel and perpendicular to the propagation plane, respectively.

Bottom: Velocity surface (left) and particle motion trajectories (right) of the two split shear waves for the Olivine model from Kasahara et al. (1968a). (b : Right), Variation of phase velocities for the Crack model, as a function of angle between the wave propagation direction and the crack normal. The density of cracks is fixed as 0.1 , with five different aspect ratios $(0.1,0.05,0.03,0.01,0.001)$ from KANESHima (1988). The quasi-shear wave polarized in the crack plane and is indicated by $q \mathrm{~S}_{1}$, while the quasi-shear wave polarized at a right angle with $q \mathrm{~S}_{1}$ is denoted by $q \mathrm{~S}_{2}$.

(位相速度が伝播方向に依存する)，またいずれの二つむ 互いに重ならない(縮退が解ける). 異方性が強くない限 りこれらの内の二つは近似的に $\mathrm{S}$ 波的振る舞いをする が (quasi-shear wave), 振動方向は完全には波線と直交 せず純粋な剪断波でなくなる。これらを $q \mathrm{~S}(1,2)$ と表記 する事にしょう．当然各波の振動べクトルが互いに直交 する性質は保存される。ここで重要な点を繰り返すと, $\mathrm{S}$ 波は互いに直交する振動べクトルと異なる速度を持っ た二つの S 波に分離して伝播する (Fig. 1). この現象を $\mathrm{S}$ 波のスプリッティング (shear wave splitting) と呼ぶ [CRAMPIN (1978)].

地球内部の媒質に異方性を生じさせる原因としては, かんらん石 (olivine) と微小割れ目 (クラック) の選択配
向を想定する場合が多いので，ここではこの二つの場合 について概観しょう．かんらん石の結晶格子が同じ方向 に並んでいると媒質は斜方晶系 (orthorhombic system) の異方性を持ち， $\mathrm{a}$ 軸の近傍を除く方向では $\mathrm{a}$ 軸と平行 に振動する $\mathrm{S}$ 波 $\left(q \mathrm{~S}_{1}\right)$ の方が a 軸之直交方向に振動する $\mathrm{S}$ 波 $\left(q \mathrm{~S}_{2}\right)$ より大きな速度を持つ（Fig. 2a［笠原・他 (1968a)])。クラックが平行に並んでいる場合, 媒質はク ラック面の法線のまわりに軸対称 (axi-symmetry, hexagonal system) となる [CRAmpin (1978), Hudson (1981)]. そしてクラック面内に振動ベクトルを持つ $q \mathrm{~S}_{1}$ 波の方が，それに直交する $q \mathrm{~S}_{2}$ 波よりも大きな速度で伝 わる (Fig. 2b) が，これは以下のように理解できる. ク ラック群の存在により $q \mathrm{~S}_{1}$ と $q \mathrm{~S}_{2}$ 各々の持つ剪断応力 
に対する剛性が互いに異なる．その剛性の差がこれらの $\mathrm{S}$ 波間の伝播速度の差となって現れ，スプリッティング が起こる. 上記のようなクラックやかんらん石による異 方性媒質中では， $\mathrm{S}$ 波スプリッティングの結果異方性軸 に対し広範囲の出射方向で震源の $\mathrm{S}$ 波振動ベクトルに よらず同一方向に振動する S 波が初動として観測され る.つまり $\mathrm{S}$ 波初動が偏光（向）しているように見える [CRAMPIn and M'CGOnigle (1981)]. それゆえこの現象 を「偏光異方性」(shear wave polarization anisotropy) と呼ぶことあある。

\section{§ 3. 観測例と地球科学的意義}

岩石の異方性による $\mathrm{S}$ 波スプリッティングは，さまざ まな空間的スケールで検出される. 高々数 $\mathrm{cm}$ 程度の大 きさの鉱物資料や [笠原・他 $(1968 \mathrm{~b})$ 等] 岩石資料 [NUR and Simmons (1969), 高橋・他 (1984) 等]に対す る弾性波速度実験で, 振動方向により異なる $\mathrm{S}$ 波 $(\mathrm{MHz}$ オーダーの周波数）の速度が観測されている。また鉱山 内の坑道の掘削に誘起された数 $\mathrm{m}$ 規模の極微小地震 （山はね）の波形にも, $\mathrm{S}$ 波（約 $2 \mathrm{KHz}$ ) のスプリッティ ングが認められる [Young et al. (1989)]. さらに井戸 (borehole) の中に 3 成分地震計を設置し地表面の人工 震源（通常数 $10 \mathrm{~Hz}$ の波を発生する）加出た波を記録 する VSP (vertical seismic profilling) 実験を通じて, S 波見かけ速度が振動方向に依存する事が分かり，地殻浅 部（約 $2 \mathrm{~km}$ 以浅）に数 $100 \mathrm{~m}$ 規模の地震波異方性によ る $\mathrm{S}$ 波スプリッティングが検出された。［例えば， LEARY et al. (1987), Li et al. (1988)].

以上の, 比較的小規模の異方性に関する研究には深入 りせず，次節からはさらに大規模な地殻深部之上部マン トルの異方性の研究についてより詳しく紹介する事にし よう.

\section{§4. 地殼深部の異方性}

\section{1 地殻深部異方性による $\mathrm{S}$ 波スプリッティングの 観測}

大陸（島弧を含む）地殼の研究では， $\mathrm{S}$ 波スプリッ ティングとそれに伴う S 波初動の偏光の観測が最有力 な異方性の検出法である. 地款には時に数 $10 \%$ にも達 する著しい速度不均質が存在するから, 異方性による $\mathrm{P}$ 波や短周期表面波速度の方位依存性を検出するすること 容易ではない， S 波スプリッティングの解析では，入射 方向の関数として S 波初動の振動方向および, 互いに直 交な方向に振動する二つの $\mathrm{S}$ 波間の到達時間差を測定 する. 異方性が著しく強くない限り分離した二つのS 波 は震源からほとんど同じ経路を伝わって観測点へ達す
る.したがって地殼の不均質は, $\mathrm{P}$ 波や短周期表面波に 対する程には, これらの測定量とくに初動の振動べクト ルに影響しない。

地殼深部の異方性による $\mathrm{S}$ 波スプリッティングの研 究は今のところ自然地震の解析に限られる. GUPUTA (1973) はネヴァダ地方の地震波形の解析から, 地殼の異 方性による S 波スプリッティングを報告している。しか し彼の波形解釈には若干の誤りがあって確かな証拠とは 言えない [CRAMPin etal. (1981)]. Yegorkina et al. (1977) はアルメ二ア地方の地殼の異方性による S 波ス プリッティングを観測しているが，データの質は必ずし あ良いとは言い難い. 1980 年代に入り英国地質調查所 のCrampin のグループが，独自の方法で S 波スプリッ ティングを検証した [CRAMPIN et al. (1980)]. 彼らはア ナトリア断層で行った地震観測から得られた多数の微小 地震波形デー夕を用い, 水平面内の $\mathrm{S}$ 波振動による particle motion を詳細に検討して, 入射方向や入射角によ らず $\mathrm{S}$ 波初動が偏光している事を見つけ，スプリッティ ングの結果であると推論した. 先述のように $\mathrm{S}$ 波初動の 振動べクトルは散乱など不均質構造に左右されにくいと いうことああり，彼らの手法は地款の異方性を見つける のに有効であった．以後同種の手法を用いた研究が数多 く行われた [例えば, BоOTH et al. (1985), KANESHIMA et al. (1987, 1988), РеACOCK et al. (1988)]. このような地 款深部の研究では通常, 地表面での $\mathrm{S}$ から $\mathrm{P}$ への変換 とそれに伴う S 波波形（SV 成分）の位相の変化を避け るために観測点直下付近の地款内地震が解析に選ばれ る. 観測システム特にダイナミックレンジの問題から微 小地震が選ばれる事が多く, 解析に用いられるのは通常 $5 \sim 10 \mathrm{~Hz}$ 程度の $\mathrm{S}$ 波波形である. 日本列島は地震活動 が活発で, さらに世界でも有数の微小地震観測網が整備 されている事もあり, 地壳内部の微小地震を用いた研究 には適していると言えよう [KANESHIMA (1990)]. 一方 海洋地款でも，STEPHEN (1985) が大洋底に掘削された 井戸 (borehole) 中の三成分地震計の記録した水中爆破 の波形を解析し, 海洋地殼の上層部（深さ $2 \sim 3 \mathrm{~km}$ ) の 異方性によると思われる $\mathrm{S}$ 波スプリッティングを検出 している.

\section{2 地款深部の異方性}

世界各地で行われた地殼内部の自然地震を用いた S 波スプリッティングの研究から，以下に述べるような幾 つかの事実が明らかになった [CRMPIN (1987), LEARY et al. (1990) 等].

（1） S 波スプリッティングを起こした異方性は，震源 領域（通常深さ $5 \sim 15 \mathrm{~km}$, 最上部マントルの地震も使 われる時は 5〜 50 km) と地表面の間の地壳内にある. 

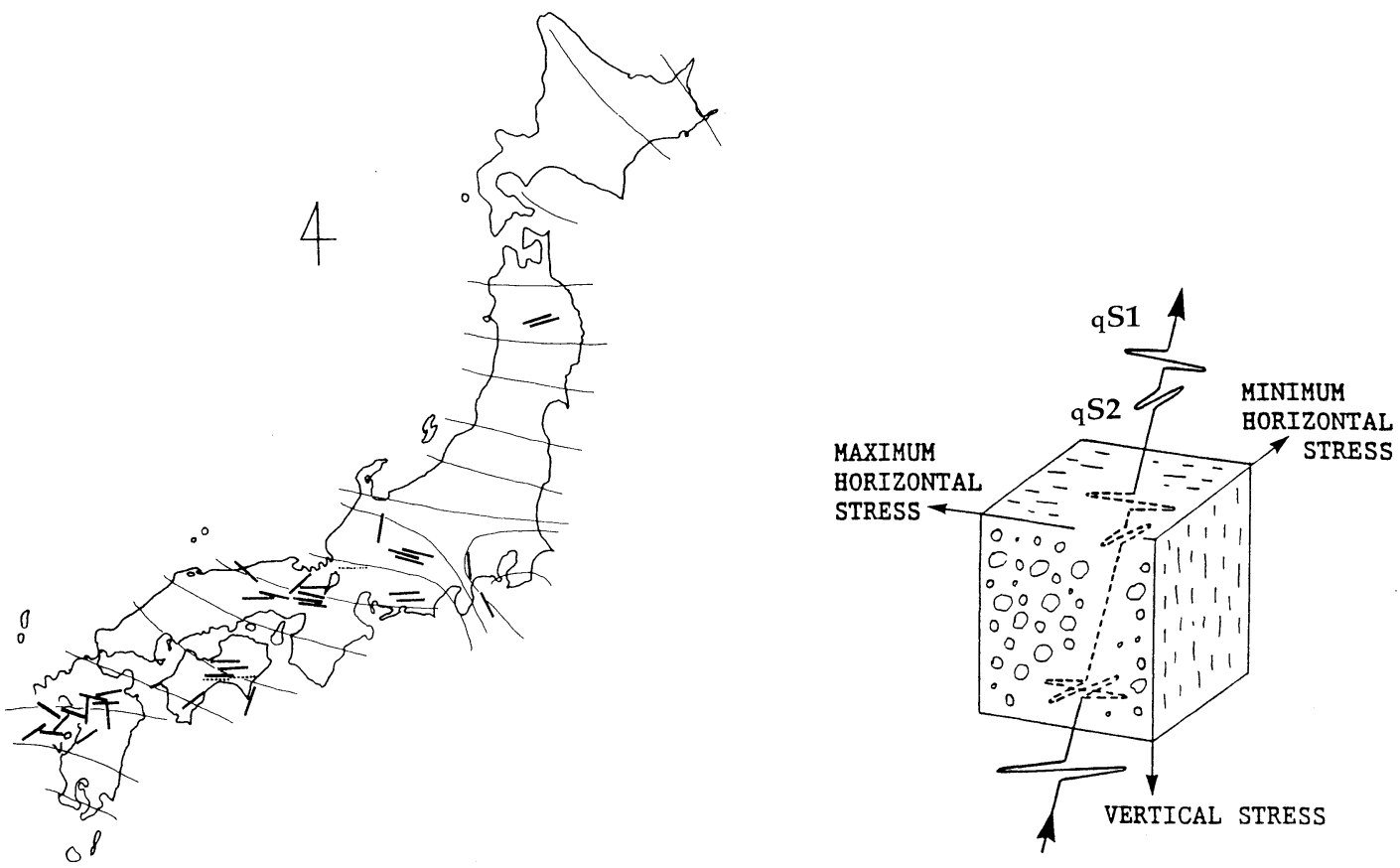

Fig. 3. (a : Left), Faster split shear wave polarization directions (bars) at the corresponding locations in the map of Japan from Kaneshima (1990). Solid and dashed bars indicate reliable and less reliable data, respectively. The trajectories of the maximum horizontal compression are given by thin solid lines. (b : Right), Schematic drawing of shear wave splitting in a stress-induced-cracked medium from Kaneshima (1990). Principal stress is taken to be positive for compression.

多くの場合，近接する複数の観測点でほぼ一様な観測結 果を示し異方性は水平方向に少なくとも数 $\mathrm{km}$ は一様 と考えられる [KANESHIMA (1990)].

(2) 地款応力と異方性の軸の間には明かな相関が見 られる.すなわち, 多くの観測点でより高速度で伝わる $\mathrm{S}$ 波の振動ベクトル ( $\mathrm{S}$ 波初動) が, 他の手法で推定され た水平圧縮応力軸とほぼ同じ方向を持つ (Fig. 3a). 地壳 内部では，一般に非静水压的な応力（差応力）が働き， 最大主応力軸（以下，主応力は圧縮の場合を正にとる） に平行かつ最小主応力軸に垂直な無数の微少割れ目（ク ラック）が存在すると考えられる．前節で述べた様に岩 石内のクラック群は全体としての岩石の弾性的性質に異 方性をむたらし，クラック面に平行に振動する S 波に対 しては媒質の剛性率を下げないから，この波が初動と なって観測される ( $q \mathrm{~S}_{1}$ : Fig. 2b, Fig. 3b). 上述の地壳応 力と $\mathrm{S}$ 波異方性の相関は, 地殼には水平面内に最大主応 力軸を持つ応力場が存在し地殼異方性がこの応力場のも とで発生したクラックに起因するものである事を示して いる [CRAMPIN (1987), KANESHIMA (1990)]. 岩石破壊試 験では, 差応力の主軸や大きさの変化に伴いクラックの 密度及び個々のクラック走行や厚さが変ることによっ て, 弾性率の異方性屯変化する事が分かっているが, 実
際の地款ではどうだろうか。以前から地震による破壊の 前にクラック密度が増加し, 周囲から水の流入を招いて 地震波速度が変化する可能性（ダイラタンシー）が唱え られてきたが [NuR (1972), Scholz et al. (1973)], S 波の スプリッティングを利用して地款の応力状態の変化に伴 う異方性の時間变化を検出できれば, 地震発生の予知に 役立つかも知れない [GUPUTA (1973), CRAMPIN (1978, 1987)]. 実際に地震の前後で異方性の時間变化を検出し たとの報告ああるが [РEACOCK et al. (1988) 等], 散乱な よ゙不均質の波形への影響を充分に評価できていないため にまだ確かな証拠とは言い難い.

(3) 分離した二つの $\mathrm{S}$ 波間の到達時間差はほとんど の地域で 0.2 秒を越えない。この值は上部地款全域に異 方性が均一に分布しているとすれば 5\%程度の速度異方 性 $\left(\left(V_{q \mathrm{~S}_{1}}-V_{q \mathrm{~S}_{2}}\right) / V_{q \mathrm{~S}_{1}} \times 100\right)$ に対応し，これをクラック による異方性と考えるとクラック密度 $\left(\varepsilon=N * a^{3}, N\right.$ : 個数密度, $a$ ：クラック半径 [O'CONNEL and BUDIANSKY (1974)]）と呼ばれる量は 0.05 程度になる.このクラッ ク密度自体の物理的意味は必ずしも明瞭ではないが，さ らに個々のクラックの aspect ratio ( $(=b / a: b$ はク ラックの厚さ）が分かれば，より具体的な岩石の性質で ある空隙率 (porosity : $\phi=(4 / 3) \pi \nu \varepsilon)$ が推定できる. ク 
ラックの aspect ratio (2) は分離した $\mathrm{S}$ 波間の時間差の 入射方向依存性を左右し (Fig. 2b) 原理的には推定可能 だが，その他の要素，例えばクラックの傾き等の影響と の分離が難しく, 今のところ信頼できる見積りはなされ ていない。

地款深部の高い封圧 (> 約 $100 \mathrm{MPa}$ ) 下で上記の様な クラックが潰れずに存在し続けるためにはそれらは流体 で満たされていなければならないが，地壳内にはかなり 普遍的に水や $\mathrm{CO}_{2}$ 等の流体が存在すると考えられてい る [FYFE et al. (1978)] から，クラックが地款内に遍在す ると考えて不自然ではない，また深さ方向に異方性が一 様とは限らない，大陸地款の堆積と沈降の際に地表から 地下深部まで水が持ちこまれる状況を想定すると，封圧 の増加に応じてクラックの密度が深さ方向に減少しそれ と共に異方性が小さくなる事む考えられる。 それに対し 島弧地款では，スラブの脱水反応によって上部マントル から水が供給される事を考えれば，反対に地下深部ほど 異方性が大きい可能性むある.ささらに水とクラックと地 震の発生は密接に関連している筈だから, 地殻の地震活 動の高い場所ほど強い異方性を持っている事も考えられ る [KANESHIMA (1988)]. 地款内部では, クラックの存在 は媒質の透水係数 (permeability) を劇的に増加させ, 流 体（水，マグマなど）の移動を決定的に左右する. 上述 のように $\mathrm{S}$ 波スプリッティングは，地款内部のクラック の密度や形状を知る手がかりを与えるから, 鉱床の発達 や地款の形成など地質学の問題や石油探查や地熱開発な どの産業的問題にも関わる.

$\mathrm{S}$ 波スプリッティングの解析から, 上部地款（浅部の 堆積層等を除く）と下部地款では異方性の様子が違う事 が示唆されている. 鉛直方向に伝わる S 波が下部地殼で はスプリッティングを起こさないと考えられる場合が多 く，このような下部地款は等方的か，あるいは鉛直方向 の周りに軸対象な異方性（トランスバースアイントロ ピー (transverse isotropy)) を持つと考えられる. 水平 方向の速度は方位に依存しないと言う意味で，方位異方 性 (azimuthal anisotropy) を示さないと言い替える事 もできよう [KANESHIMA et al. (1988), KANESHIMA (1990)]. 最近の反射法による地殼深部探查の結果, 様々 な地域で下部地殼は上部地殼に比べはるかに高密度の水 平反射面を持つ事が分かってきた [MEISSNER (1986)]. このような反射波探查の結果を基に下部地殼では水平な 薄層が重なっている可能性も指摘されているが [SANDMEIER AND WENZEL(1986)], 水平の薄層やクラックは 全体としての媒質にトランスバースアイソトロピー型の 異方性をむたらすから，前述の S 波スプリッティングの 解析結果はこの下部地款像と矛盾しない，脆性破壊（地
震）が起こる上部地款にはクラックにより差応力を反映 した方位異方性が存在するのに対し, ほとんど地震を起 こさない下部地款が同様な方位異方性を持たないのは, 下部地款が遡性的で水平方向の差応力を支えない事を示 しているのではなかろうか.

\section{§5. 上部マントルに関する研究}

\section{$5.1 \mathrm{~S}$ 波スプリッティングの観測}

上部マントル異方性起源の $\mathrm{S}$ 波スプリッティングに 関する研究は，今まで主として次の三種の剪断波フェイ ズを用いて行われている. 近地深発地震の直達 $\mathrm{S}$ 波, 遠 地地震の $\mathrm{ScS}$ 波, 及び, SKS 波である. 後述する様に, 地表面や核マントル境界での反射などが剪断波の波形に あまり影響しない地震 一観測点の組み合わせが選ばれる ため，必ずしも同一地域にこれらすべての波が利用でき るとは限らない。

(1) 沈み込み帯の上部マントル深発地震の $S$ 波

ANDo et al. $(1980,1983)$ は中部地方下の深発地震 (深 さ約 $300 \mathrm{~km}$ ) の短周期（約 2 秒） S 波波形を解析し, 初 めて上部マントル異方性によるスプリッティングを見い だした。同種の研究が, トンガ・フィジー諸島 [Bowman and ANDo (1987)]及び, 南米, イタリア，八 ワイ [SAVAGE et al. (1989)] について行われている. し かし短周期波形には不均質の影響が大きく，さらに沈み 込み帯の上部マントルでは $\mathrm{S}$ 波の減衰が顕著で短周期 地震計に旨く記録されないなどの事ああって，良い観測 例は多くない。 また深発地震の $\mathrm{S}$ 波波形が明瞭なスプ リッティングを示さない観測点が多く, 現段階ではこの 現象は必ずしも沈み込み帯の上部マントルに普遍的なも のとは思われない。

(2) 深発地震の $\mathrm{ScS}$ 波

FuKAo (1984) は，日本各地で観測された千島諸島下 の深発地震の $\mathrm{ScS}$ 波形 (卓越周期約 5 秒) を調べて明瞭 なスプリッティングを見い出した。 一方, 安藤 (1989) は 小笠原諸島下の深発地震の $\mathrm{ScS}$ 波に同様の現象を検出 したが，日本全国で記録された ScS 波初動の方向（東 西) はFUKAO (1984)の場合（ほぼ南北）とは $90^{\circ}$ 近く異 なっていた. ScS のスプリッティングを起こした異方性 領域が伝播経路上の何処に存在するか今のところ明らか とは言えないが, 安藤 (1989) と FUKAO (1984) の結果か ら異方性領域は日本列島の観測点下の上部マントルでは なく深発地震の震源近傍にあると考えるのが妥当と思わ れる.

ANDo (1984) は環太平洋地域の多くの観測点で短周 期 WWSSN の ScS 波形（卓越周期 3〜 5 秒）にスプ リッティングが認められる事を示した (Fig. 4a). より長 

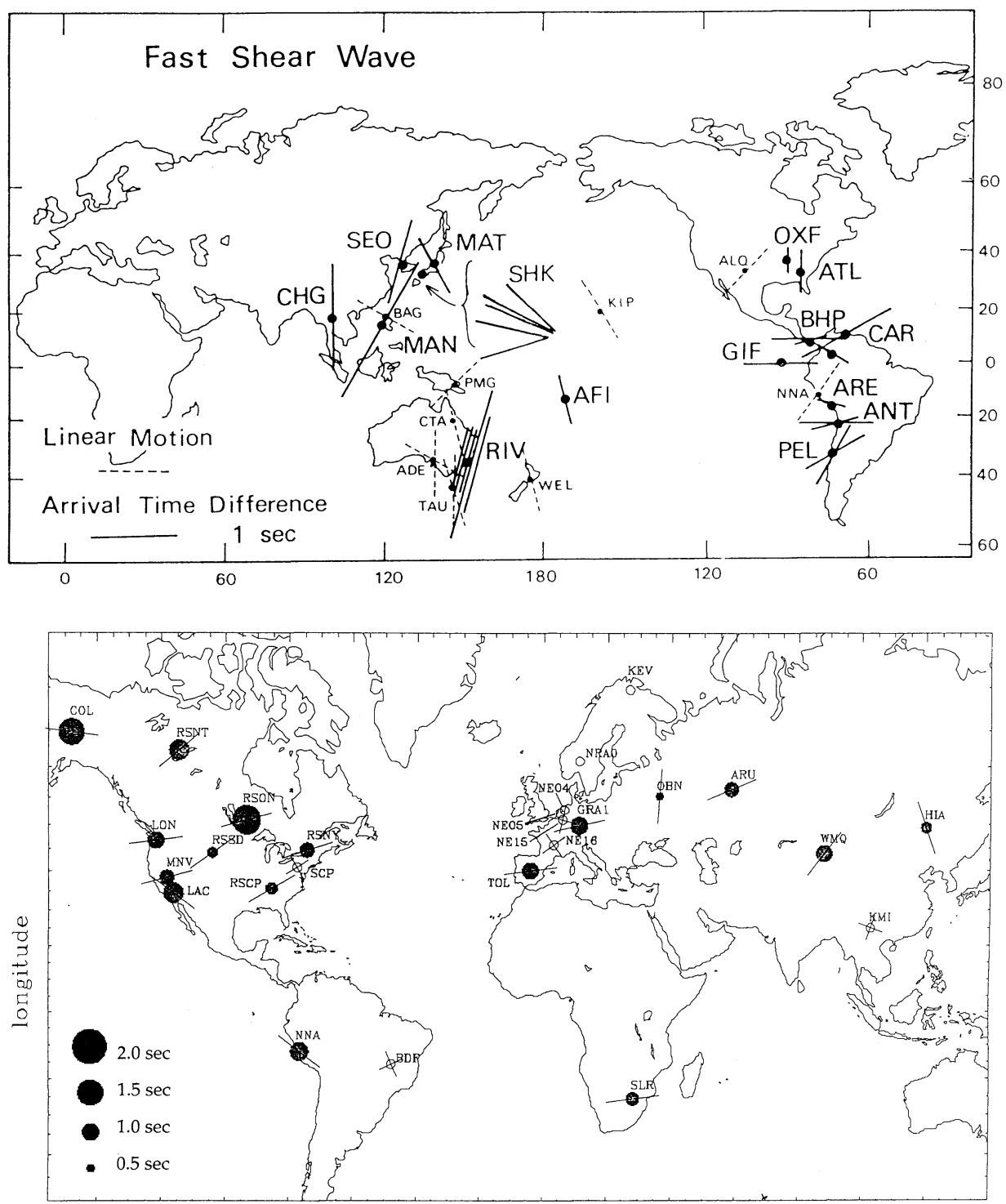

latitude

Fig. 4. (a: Top), Faster split shear wave polarization directions (solid bars) shown at the locations of the WWSSN stations from the ScS study [after Ando (1984)]. The dashed bars with a small station code show the linear particle motions possibly representing no splitting of shear waves. The length of the solid bars shows the time difference between the two split shear waves. (b : Bottom), Faster split shear wave polarization directions (bars) from SKS studies [after Silver and Chan (1991)]. The time difference between the split waves is indicated by the size of circle.

周期（卓越周期約 20 秒）の $\mathrm{ScS}$ 波に対して，同様の解 析が ANSEL and NATAF (1989) により GEOSCOPE の波 形記録を用いて行われている.

（3）遠地地震の SKS 波

震源から角距離にして $85^{\circ} \sim 130^{\circ}$ の観測点では, SKS 波が $\mathrm{S}$ 波より早く到達し，しかも孤立したフェイズとし
て明瞭に観測される. KIND et al. (1985) は，南部ドイッ の GRF アレイの広帯域デジタルの SKS (周期約 10 秒) 波形記録を解析して, 観測点下の上部マントル異方性起 源のスプリッティングを検出した. 同種の研究が GDSN [Silver and Chan $(1988,1991)]$, GEOSCOPE [VINNIK etal. (1989a), Ansel and Nataf (1989)], NARS 
[VINNIK et al. (1989a)] 等のデータを用いて行われてい る. 中でも, Silver and ChAN $(1988,1991)$ は北米, アフリカ，ユーラシア大陸の観測点で SKS 波 (周期約 10 秒) のスプリッティングを検出し, 大陸下のマントル には異方性がかなり普遍的に存在すると主張した (Fig. 4b)。 また ANSEL and NATAF (1989) の結果は大陸の縁 辺，特に環太平洋地域でも同様な SKS 波（周期約 20 秒）のスプリッティングが見られる事を示している. SKS 波は震源下のマントルー核境界 (CMB) で S から P に変換し，さらに観測点下の $\mathrm{CMB}$ で $\mathrm{P}$ から変換した $\mathrm{SV}$ 波であるから，その解析には以下のような利点があ る. まず異方性の領域を観測点と CMB の間のマントル （あるいは地壳）に特定できる. 次に，スプリッティング を起こす前の振動べクトルは動径方向 (radial) からそれ ほど大きくはずれないと考えて良いから，震源での $\mathrm{S}$ 波 の振動ベクトルを考慮しなくても良い，一方 ScS 波は $\mathrm{CMB}$ での反射の際に S から P の変換波を生じそれに伴 いS 波自身の（SV 成分の）位相が変化して波形が複雑 になり得る. ScS 波の解析ではこの影響を小さくするた め角距離にして約 $40^{\circ}$ よりも近い観測点が用いられてい るから，より遠距離の地震を用いる SKS 波の解析はこ れと相補的な重要性を持っているとも言える.

\section{2 上部マントルの異方性}

上部マントル異方性起源の $\mathrm{S}$ 波スプリッティングの 研究から得られた重要な結果として次の二点があげられ よう.

第一に, 海洋プレートの境界付近に位置する観測点 (南米, 北米の太平洋岸) 及び, 大陸の中であ比較的高速 度で移動しているオーストラリアでは, 速い S 波の振動 ベクトルは現在のプレート運動と関連している $[$ ANDO (1984)] (Fig. 4a). 上部マントルを構成する岩石の最む 主要な鉱物であるかんらん石 (olivine) は歪や流れに よって結晶格子に選択配向を生じ, 岩石全体の弾性率に 大きな異方性をむたらす。 $400 \mathrm{~km}$ 以浅の上部マントル ではこのかんらん石の選択配向が主に地震波異方性に寄 与するだろう考えられている[例えば NICOLAS and Christensen (1987)]. 汃んん石多結晶の变形実験や マントル起源のかんらん岩（ペリドタイト）の弾性波速 度の測定結果によれば, マントル最上部の温度圧力の下 での剪断流動によって，かんらん石の $\mathrm{a}$ 軸が流動方向 （伸びの方向）に，b面が滑りの面に揃う［例えば，唐戸 (1986), 竹下・唐戸 (1989), Nicolas and PoIRIER (1976)]. 速い S 波の振動ベクトルの方向が, プレート 運動あるいはそれを基に推定されたマントル対流 [HAGER and O'CONNELL (1979)] と良く一致する事から (Fig. 4a) [ANDO (1984)], マントルの対流に伴ってかん
らん石の $\mathrm{a}$ 軸が滑りの方向に揃い，a 軸に平行な振動べ クトルを持つ $\mathrm{S}$ 波がその中を早く伝わる (Fig. 2a) と解 釈できる.これに対して，アフリカ，ユーラシア，北米 などの先カンブリア紀の安定大陸では, 速い S 波の振動 ベクトルは，現在のプレート運動よりも，むしろ 20 億 年以上前に起こった最後の造山活動における圧縮方向と 直交する [SILVER and CHAN (1991)] (Fig. 4b)。 かんらん 石が圧縮を受けた場合には最大伸びの方向に $\mathrm{a}$ 軸が選 択配向する事を考えると [例えば NICOLAS and POIRIER (1976)]，この観測事実むやはりかんらん石の選択配向 で説明できそうである. 大陸下のリソスフェアーが過去 に受けた変形を失わずに保存していると考えて，これら のリソスフェアー内に拈ける温度分布あるいは差応力の 上限を見積もる事も可能だろう。

第二に, 分離した $\mathrm{S}$ 波間の時間差がどの観測点でもせ いぜい 2 秒程度で， 3 秒に達するような例は未だ観測さ れていない．また $1,000 \mathrm{~km}$ 程度離れた観測点間で異方 性の軸の方向や時間差が大きく変わる事から, 下部マン トルや $\mathrm{CMB}$ 付近ではなく上部マントルの異方性が $\mathrm{S}$ 波 スプリッティングを大きく左右していると考えられる [Silver and CHAN (1988)]. 仮に地表加 $200 \mathrm{~km}$ 以浅 の領域に異方性が一様に分布している場合を想定すると 2 秒の時間差は約 $4 \%$ の速度異方性に相当する. この值 はオフィオライトなどの測定結果 [CHRISTENSEN (1984)] 之調和的である. さらに，かんらん石の結晶の S 波異方性（最大約 15\%) 及び上部マントルの岩石中に占 めるかんらん石の比率（約 60\%），汃んらん石結晶全部 が完全に同じ方向にそろうとは限らない事，などを考え 併せても不自然な値ではない. SILvER and CHAN (1991) はさらに北米の観測点において S 波スプリッティング の時間差と $400 \mathrm{~km}$ 以浅の上部マントルの $\mathrm{S}$ 波速度異 常 [GRAND (1987)] との負の相関を見いだした。 つまり， $\mathrm{S}$ 波の走時が速い観測点ほどスプリッティングによる二 つの $\mathrm{S}$ 波の時間差は大きい. $\mathrm{S}$ 波の走時異常は大陸下の リソスフェアーの厚さを反映していると考えられるの で,この相関は異方性が大陸リソスフェアー内の現象で ある事を示している様である.

上部マントルの地震波異方性の原因として他に, 部分 溶融したメルトが一定の方向に並ぶ事も考えられる [ANDO et al. (1983)]. その様なメルトは，媒質内の割れ 目（クラック）として取り扱うことができ，媒質に働く 差応力によって支配されていると考えられるものの, 差 応力に対する応答は脆性クラックの場合ほど明らかには されていない, メルトはよる異方性は島弧, 特に火山フ ロント下の上部マントルで重要な役割を果たす可能性が ある. $\mathrm{S}$ 波スプリッティングを利用した地震波異方性の 
研究はメルトの形状などを推定するのに役立つと思われ る.

\section{3 他の地震学的研究との関連}

上部マントル内部の大規模異方性に関しては, 長周期 表面波 (周期 30 400 秒) や自由振動の解析からもその 実態が明らかにされつつある [中西(1988)]. 本稿の最 初に触れたように，表面波に関わる異方性現象には， ラ ブ波とレイリー波から求められた速度構造の食い違い （表面波の polarization anisotropy と呼ぶ) [DzIEwONSKI and ANDERson (1981), REgAN and ANDERSON (1984)] と, 位相速度（特にレイリ一波の）の方位依存性 (azimuthal anisotropy) [TANIMOTo and ANDERSON (1984), Montagner and TAnimoto (1990)] がある. 前 者の polarization anisotropy は, 多くの方位を平均す れば上部マントルはトランスヴァース・アイソトロピー 型の異方性を持つことを意味するのだが，遠地地震を用 いる限り観測点下の上部マントルでは波線はほぼ鉛直だ から S 波スプリッティングはこのタィプの異方性に対 して敏感ではない. 従って後者の位相速度方位異方性の みが $\mathrm{S}$ 波スプリッティングと関連すると考えて良い。

$\mathrm{S}$ 波スプリッティング解析で伝播経路の速度構造に左 右されない観测量は先着 $\mathrm{S}$ 波の振動ベクトルと分離し た二つの S 波間の時間差だが, 振動ベクトルは表面波位 相速度の方位異方性と比較的容易に対照できる。レイ リ一波は水平に伝わる実体波 S 波の SV 成分に対応し た剪断応力を持つ. かんらん石による異方性で a 軸が水 平の場合を考えれば，レイリ一波 (Fig. 2a: (010) あるい は (001) 面内を伝わる $q \mathrm{SV}$ 波に対応する) は $\mathrm{a}$ 軸方向 に最大の速度を持つ [CRAMPIN and TAYLOR (1971)]. 従って S 波初動の振動べクトルは位相速度最大の方向 と一致する. ANDO (1984) は, 環太平洋地域で, $\mathrm{ScS}$ 波 初動の振動ベクトルが上部マントルレイリー波 (周期約 200 秒）の最大速度の方向 [TANIMOTO and ANDERSON (1984)] と調和的であることを指摘したが (Fig. 4a), こ の結果はかんらん石異方性モデルが妥当である事を示し ている.

それに対し時間差を異方性の大きさに換算し表面波解 析の結果と対照するためには，まず異方性領域を特定せ ねばならない，今のところ， $\mathrm{S}$ 波スプリッティングのみ から独立に異方性領域を推定する事は困難で, 何らかの 仮定を設けざるを得ない，領域を仮定すると，SKS ある いは ScS 波線の入射方向によって様々な弾性定数の組 み合わせを推定できる，表面波の異方性から知る事ので きる弾性定数の線形結合は実質上固定されているから [例えば，MONTAGNER and NATAF (1986)]，S 波スプ リッティングは異方性のより詳細な推定に役立つ可能性
を秘めている。、いずれにしても, マントル異方性の領域 や大きさや軸の方向をを知るには表面波と S 波のデー 夕を総合する事が望ましいのであるが，先述した ANDO (1984) の研究の他は今のところ表面波と $\mathrm{S}$ 波のスプ リッティングの研究結果の本格的な比較検討はなされて いない，これは，表面波方位異方性の研究の多くが太平 洋やインド洋など海洋に対して行われているのに対し海 洋プレート上の観測点での S 波スプリッティングの信 頼できる研究がまだない事による. 一方, 北米など大陸 ではSKS のスプリッティングが明瞭に見られるが，全 地球的表面波方位異方性モデル [TANIMOTO and ANDERSON (1984), MontAGNER and TANimoto (1990)] の同 地域に対する解の安定性は余り良くない，表面波は水平 方向の広い範囲の平均的な構造を反映するから，水平方 向の解像度は短周期 S 波のスプリッティングよりも劣 る事は明かである。一方深さ方向には, 次節で述べる様 に S 波スプリッティングの解像力は低く, 広い周波数帯 の位相速度を扱う事のできる表面波解析の方がむしろ高 い解像度を実現している様である。

$\mathrm{S}$ 波スプリッティングと Pn 波の方位異方性の比較 屯, 海洋プレート上での S 波スプリッティング観測例が 少ないためまだ充分にはなされていない.ただし大陸で は若干の比較例がある. 南部ヨーロッパで GRF のデー 夕を使った SKS のスプリッティング解析の結果 [VINNIK et al. (1989b)], Pn 波の最大速度の方向 [BAMFORD (1977)] と SKS 波初動の振動方向に $60^{\circ}$ 以上の食 い違いが見られた. かんらん石の結晶格子配向による Pn 波速度の方位異方性を考えると, 最大速度の方向は a 軸と一致するはずである（Fig. 2a: (001) あるいは (010) 面内での $q \mathrm{P}$ 波). 従って SKS 波のスプリッティ ングと Pn 波速度の方位依存性は異なる領域の異方性を 反映している可能性がある.つまり, Pn 波はマントル最 上部の（恐らくはモホ面直下付近の）薄い領域の異方性 を，一方長周期の SKS 波はそれとは異なったより深部 の異方性を反映し最上部の薄い異方性の存在をほとんど 感じていないと考えられる。同様なPn 波の方位異方性 とSKS 異方性の食い違いは北米の Basin and Range で も見られる [SILVER and CHAN (1991)].

\section{§6. 今後の課題}

地震波異方性研究の最大の目的は, 上部マントルや地 殻など地球内部の弾性定数の推定を通じて, そこに存在 する物質を同定しさらに変形や応力の状態を知る事にあ る. その際により多くの弾性定数が分かっていればそれ だけ地球内の物質モデルや变形モデルなどの任意性を小 さくできる事は言うまであない. $\mathrm{S}$ 波スプリッティング 
は有力な地震学的異方性研究の手段であるものの, その 現状はかんらん石やクラックによる成層構造的な異方性 モデルを仮定した場合に $\mathrm{a}$ 軸やクラックの走向のみが 推定できると言うところで, 異方性の三次元的な分布の 状態や a 軸やクラックの傾きについては任意性が大き い. $\mathrm{a}$ 軸やクラックの走向だけを議論する限りこれらの モデルは他の地球科学的データに照らして妥当なもので あるが, 異方性の存在領域やかんらん石の $\mathrm{a}$ 軸やクラッ クの傾きをも含めた推定が可能となった時点で改めてそ の妥当性を再検討する必要があると思われる. 上部マン トルに関しては, MONTAGNER and NATAF (1988) 等が 表面波位相速度のデータから異方性軸の走向だけでなく 傾きまで推定しようと試みているが， $\mathrm{S}$ 波スプリッティ ングからも同様の試みがなされる事が期待される。しか しそのためには以下に述べるようにまだ解決しなくては ならない難問が数多く残されている.

$\mathrm{S}$ 波スプリッティングは短い波長の実体波（実質上周 期 20 秒以下）の現象であり，局所的構造に大きく左右 され単純な解釈が難しい場合が多い. マントル異方性に 関するこれまでの観測結果は, 地球内部の大規模なダイ ナミクスと異方性の相関を示唆する一方, 観測点間のば らつき屯大きい. 残念ながら観測結果がどの程度局所的 な現象かを判定するほど密な観測点網のデー夕は少ない [比較的密度の高い観測データを用いた例としては VINNIK et al. (1989a), SAVAGE et al. (1990) がある]. マ ントル異方性研究では多くの場合遠地地震の解析に頼ら ざるを得ないから観測点下のマントルでは S 波はほぼ 鉛直方向に伝わる. $\mathrm{S}$ 波スプリッティングは波線に沿っ た異方性の積分值を反映するから，深さ方向の解像度は 非常に弱い事になる。 さらに地震と観測点の分布によっ て, 入射方位も各観測点で著しく限られる，異方性を詳 細に推定する上でのこれらの障害を除くためには，多様 な剪断波フェイズ（S 波, SS 波, $\mathrm{PcS}$ 波など）を用いて 可能な限り広い入射方向のデータを蓄積する必要があ る. 例えば遠地地震の S 波は SKS 波に比べて，広い領 域のマントルの異方性や不均質を反映するからより多く の情報を持っている筈である. しかしその反面, 震源過 程の影響を考慮しなくてはならないなど取扱いが複雑な るためかまだ良い結果は得られていない，また水平方向 の解像力の高さを生かして異方性領域の位置と広がりを より詳しく決定する事も今後の重要な課題となる。同目 的に対しては，広い周波数帯の S 波波形を用いてスプ リッティングの周波数依存性を調べる事も有効と思われ る.しかし分離した S 波間の時間差が 3 秒に達する観測 例が無い事実は 20 秒以上の長周期 S 波の利用が有効で ない事を示す.さらに地動の雑音（特に，通常 5〜10 秒
にピークを持つ microseisms）の存在, 伝播距離が長い 事による高周波成分の減衰, 大地震ほど一般的に震源過 程も複雑で $\mathrm{S}$ 波波形の取扱いも難しくなる事などから， 広帯域における $\mathrm{S}$ 波スプリッティングの解析は容易で はない.

地款深部異方性に関しても，上部マントルの場合と同 様 $\mathrm{S}$ 波スプリッティングには深さ方向の低解像力がつ きまとう。ただし地殻の場合，地域によっては深さや入 射角の大きく異なる地震を用いる事でこの難点をある程 度克服する事ができる [KANESHIMA et al. (1988)]. S 波 初動の偏光を利用した異方性の検出は, 地殻の不均質に 比較的鈍感である点で有効であった。しかし，観測点近 傍の地表面の不規則性や媒質の不均質は P 波コーダを 励起して S 波初動の同定を困難にし, 当然のごとく S 波 波形にも大きな影響をむたらす。これら地殻の不均質及 び地表面の影響を評価するためには高密度の群列（アレ イ）微小地震観測を行う必要がある。 また， $\mathrm{S}$ 波スプ リッティングの確認のためには波形解析に用いた微小地 震の発震機構 (断層面解) についての詳細な情報が不可 欠となり，これまた高密度かつ広範囲の観測点網を必要 とする，異方性の観点から見た上部地殼と下部地殻の違 いは今後解明されるべき重要な問題であるが，地表の影 響を小さくするための入射角の制限によって下部地殻を 水平に近い角度で伝わる $\mathrm{S}$ 波を利用できない事がこの 問題の解決に対して障害となっている.この制限を除く 方法の一つは, 深井戸 (deep well) の中で観測された 3 成分波形を解析することであろう。また現在観測デー夕 の解釈に適用されている長波近似（S 波波長が個々のク ラックのサイズよりも充分に長い [HudSoN (1981)]）に は, クラックのサイズを特定できないという限界があ り, コーダ Q の解析結果など他の地球物理学的データと の照合を困難にしてきた。地壳異方性研究の場合, 広帯 域広ダイナミックレンジの観測を行えば，マントルの研 究と比べて比較的容易に, 広い周波数帯の波形が解析可 能になるだろう。このような観测と平行して，波長とク ラックが同程度の場合における理論の発展が望まれる.

本稿では, 地球内部の異方性領域として上部マントル と上部地款を集中的に取り扱った。 それは同領域に対し ては異方性に関するデータが他の地球内部領域に比へ圧 倒的に豊富であるからで, 他領域の異方性が地球科学的 に重要でないとかその存在が明らかに否定されていると いう意味ではない，たとえば現在マントル最下部（D” 層）や内核にも地震波異方性が存在するのではないかと 考えられている. S 波スプリッティングはこれらの領域 を調べる上でどんな役割を果たし得るだろうか. D” 層 は核とマントルの相互作用の場であり, 非常に大きな温 
度勾配を持つ領域である. 以前から，下部マントルの中 では特別に地震波速度不均質の大きい領域として注目さ れてきたが，外核からの熱の流入などにより大規模な変 形が生じそれに伴って異方性を帯びている可能性も高 い.これまでにも, D”層にトランスヴァース アイソト 口ピーが存在し SH 波速度が SV 波速度よりも大きい可 能性が示唆されている [DooRnBos et al. (1986)]. とすれ ば同層内を伝わる $\mathrm{S}$ 波にスプリッティングが起こり，そ れが観測にかかるかも知れない. 一方, 内核の異方性は, そこでの鉄の結晶格子の種類や対流・変形の様子につい ての貴重な情報を与える. 内核の異方性については P 波 走時の方位依存性や自由振動の研究からその存在が提唱 されているが [MORELli et al. (1986), WoODHOUSE et al. (1986)]， 内核を伝わる $\mathrm{S}$ 波（PKJKP 波）のスプリッ ティングが検証されるとより直接的で決定的な証拠にな る.しかしながら現在ではまだ PKJKP 波自体の検出が 確認されていない段階である. その検出には高密度の観 測点アレイの利用が必須だが，内核での $\mathrm{S}$ 波短波長成分 の減衰が大きいために短周期地震計（固有周期 1 秒程 度）のアレイによる検出は困難と予想される [DooRnBos (1974)]. 将来広帯域地震計の高密度アレイ観測が実現さ れればより減衰の小さい長波長の $\mathrm{S}$ 波が検出されるか も知れない.

\section{文献}

AkI, K. and P. G. Richards,1980, Quantitative seismology: theory and methods, Freeman, New York, pp. 932.

Ando, M., Y. Ishikawa and H. WADA, 1980, S-wave anisotropy in the upper mantle under a volcanic area in Japan, Nature, 286, 43-46.

安藤雅孝, 1989, スラブ内の異方性, 海洋， 21, 90-96.

Ando, M., Y. IshikAw a and F. YAmazAKI, 1983, Shear wave polarization anisotropy in the upper mantle beneath Honshu, Japan, J. Geophys. Res., 88, 58505864 .

Ando, M., 1984, ScS polarization anisotropy around the Pacific ocean, J. Phys. Earth, 32, 179-196.

Ansel, V. and H.-C. NATAF, 1989, Anisotropy beneath 9 stations of the GEOSCOPE broadband network as deduced from shear-wave splitting, Geopys. Res. Lett., 16, 409-412.

BAMFord, D., 1977, Pn-velocity anisotropy in a continental upper mantle, Geophys. J. Roy. Astr. Soc. 49, 29-48.

Booth, D. C., S. Crampin, R. Evans and G. Robert, 1985, Shear-wave polarizations near the north Anatolian Fault: I, evidence for anisotropy-induced shear-wave splitting, Geophys. J. Roy. Astr. Soc., 83, 61-73.
Bowman, J. R. and M. Ando, 1987, Shear-wave splitting in the uppermantle wedge above the Tonga subduction zone, Geophys. J. Roy. Astr. Soc., 88, 25-41.

Christensen, N. I., 1984, The magnitude, symmetry and origin of uppermantle anisotropy based on fabric analyses of ultramafic tectonics, Geophys. J. Roy. Astr. Soc., 76, 89-111.

CRAmpin, S., 1981, A review of wave motion in anisotropic and cracked elastic-medium, Wave Motion, 3, 343-391.

Crampin, S., 1987, Geological and industrial implications of extensive-dilatancy anisotropy, Nature, 328, 491-496.

CRAMPIN, S., 1978, Seismic wave propagation through a cracked solid: polarization as a possible dilatancy diagnostic, Geophys. J. Roy. Astr. Soc., 53, 467-496.

CRAmpin, S. and D. B. TAYLOR, 1971, The propagation of surface waves in anisotropic media, Geophys. J. Roy. Astr. Soc., 25, 71-87.

CRAmpin, S. and R. McGonigle, 1981, The variation of delays in stress-induced polarization anomalies. Geophys. J. Roy. Astr. Soc., 64, 1115-1131.

Crampin, S., R. Evans, M. Ucer, J. Doyle and J.P. DAvis, 1981, Comments on papers about shearwave splitting in dilatancy-induced anisotropy by I. N. GUPUTA and by A. RYALL and W. U. SAVAGE, Bull. Seism. Soc. Am., 71, 375-377.

Crampin, S., R. Evans, M. Doyle, P. Davies, G. V. YegorkinA and A. Miller, 1980, Observations of dilatancy-induced polarization anomalies and earthquake prediction, Nature, 286, 874-877.

DAHLEN, F.A., 1972, Elastic velocity anisotropy in the presence of an anisotropic initial stress, Bull. Seism. Soc. Am., 62, 1183-1193.

Doornbos, D. J., 1974, The anelasticity of the inner core, Geophys. J. Roy. Astr. Soc., 38, 397-415.

Doornbos, D. J., S. Spilioroulos and F.D. Stacey, 1986, Seismological properties of D" and the structure of a thermsl boundary layer, Phys. Earth Planet. Interiors, 41, 225-239.

Dziewonski, A. M. and D. L. Anderson, 1981, Preliminary reference earth model, Phys. Earth Planet. Interiors, 25, 297-356.

FukAo, Y., 1984, Evidence from core-reflected shear waves for anisotropy in the Earth's mantle, Nature, 309, 695-698.

Fyfe, W. S., N. J. Price and A. B. Thompson, 1978, Fluids in the Earth's crust, Elsevier, New York, $383 \mathrm{pp}$.

GRAND, S. P., 1987, Tomographic inversion for shear velocity beneath the North American plate, J. Geophys. Res., 92, 14065-14090.

Guputa, I. N., 1973, Premonitory variations in S-wave velocity anisotropy before earthquakes in Nevada, Science, 182, 1129-1132. 
Hager, B. and O'connell, 1979, Kinematic models of large-scale flow in the Earth's mantle, J. Geophys. Res., 84, 1031-1048.

Hudson, J. A., 1981, Overall properties of a cracked solid, Math. Proc. Camb. Phil. Soc., 88, 371-384.

Kaneshima, S., M. Ando and S. Crampin, 1987, Shearwave splitting above small earthquakes in the Kinki district of Japan, Phys. Earth Planet. Interiors, 45, 45-58.

Kaneshima, S., M. Ando and S. Kimura, 1988, Evidence from shear-wave splitting for the restriction of seismic anisotropy to the upper crust, Nature, $335,627-629$.

Kaneshima, S., 1988, Crustal anisotropy: evidence from shear-wave splitting studies in Japan, PhD. Thesis, Kyoto Univ., Kyoto, 45 pp.

Kaneshima, S.,1990, Origin of crustal anisotropy: shear-wave splitting studies in Japan, J. Geophys., 95, 11121-11133.

唐戸俊一郎，1986, 地震波速度異方性のメカニズム, 唐 戸俊一郎・鳥海光弘編「固体と地球のレオロジー」, 東 海大学出版会, 東京, 312-333.

笠原順三・鈴木 功・熊沢峰夫・飯田汲事, $1968 \mathrm{a}$, 異 方性媒質中の平面波速度と球面波速度扰よ゙ェネル ギー伝播, 地震 2, 21, 282-292.

笠原順三・鈴木 功 - 熊沢峰夫 - 飯田汲事, 1968b, Dunite のS 波異方性，地震 2, 21, 229-236.

Kind, R., G. L. Kosarev, L. I. Makeyeva and L. P. VINNIK, 1985, Observations of laterally inhomogeneous anisotropy in the continental lithosphere, Nature, 318, 358-361.

Leary, P. C., Y.-G. Li and K. Akı, 1987, Observation and modelling of fault-zone fracture seismic anisotropy-I. P, SV and SH travel times, Geophys. J. Roy. Astr. Soc., 91, 461-484.

Leary, P. C., S. Crampin and T. V. Mcevilly, 1990 , Seismic fracture anisotropy in the Earth's crust: an overview, J. Geophys. Res., 95, 11105-11114.

Li, Y.-G., P. C. Leary and T. L. Henyey, 1988, Stress orientation inferred from shear-wave splitting in basement rock at Cajon Pass, Geophys. Res. Lett., 15, 997-1000.

Meissner, R., 1986, The continental crust: a geophysical approach, Academic Press, Florida, 426 pp.

MochizUKi, E., 1986, The free oscillations of an anisotropic and heterogeneous Earth, Geophys. J. Roy. Astr. Soc., 86, 167-176.

Montagner, J.-P. and H.-C. Nataf, 1986, A simple method for inverting the azimuthal anisotropy of surface waves, J, Geophys. Res., 91, 511-520.

Montagner, J.-P. and H.-C. NAtAF, 1988, Vectorial tomography-I. Theory, Geophys. J., 94, 295-307.

Montagner, J.-P. and T. TAnimoto, 1990, Global anisotropy in the upper mantle inferred from the regionalization of phase velocities, J. Geophys. Res., 95, 4797-4819.

Morelli, A., A. M. Dziewonski and J. H. Woodhouse,
1986, Anisotropy of the inner core inferred from PKIKP travel times, Geophys. Res. Lett., 13, 15451548.

Musgrave, M. J. P., 1970, Crystal acoustics, Holdenday, San Francisco, 288 pp.

中西一郎, 1988, 地球内部構造に関する最近の地震学的 研究, 地震 $2,41,133-144$.

Nicolas, A. and N. I. Christensen, 1987, Formation of anisotropy in upper mantle peridotites-A review, in "Composition, Structure and Dynamics of the Lithosphere-Asthenosphere System", Geodynamic Ser., 16, ed. by K. Fuchs and C. Froidevaux, AGU, Washington D. C., 111-123.

Nicolas, A. and J. P. Poirier, 1976, "Crystalline plasticity and solid state flow in metamorphic rocks", John Wiley \& Sons, New York, 444 pp.

Nur, A., 1972, Dilatancy, pore fluids, and premonitory variations of ts/tp travel times, Bull. Seism. Soc. Am., 62, 1217-1222.

Nur, A. and G. Simons, 1969, Stress-induced velocity anisotropy in rock: an experimental study, J. Geophys. Res., 74, 6667-6674.

O'connell, R. J. and B. Budiansky, 1974, Seismic velocities in dry and saturated cracked solids, J. Geophys. Res., 79, 5412-5426.

Peacock, S., S. Crampin, D. C. Booth and J. B. FletcHER, 1988, Shear-wave splitting in the Anza seismic gap southern California: temporal variations as possible precursors, J. Geophys. Res., 93, 33393356.

Regan, J. and D. L. Anderson, 1984, Anisotropic models of the upper mantle, Phys. Earth Planet. Interiors, 35, 227-263.

SAndmeier, K.-J. and F. Wenzel, 1986, Synthetic seismgrams for a complex crustal model, Geophys. Res. Lett., 13, 22-25.

Savage, M. K., X. P. Shih, R. P. Peyer and R. C. Aster, 1989, Shear-wave anisotropy of active tectonic regions via automated S-wave polarization analysis, Tectonophysics, 165, 279-292.

Savage, M. K., P. G. Silver and R. P. Meyer, 1990, Observations of teleseismic shear-wave splitting in the Basin and Range from portable and permanent stations, Geophys. Res. Lett., 17, 21-24.

Scholz, C. H., L. R. Sykes and Y.P. Aggarwal, 1973, Earthquake prediction: a physical basis, Science, 181, 803-810.

Silver, P. G. and W. W. Chan, 1988, Implications for continental structure and evolution from seismic anisotropy, Nature, 335, 34-39.

Silver, P. G. and W. W. Chan, 1991, Shear wave splitting and subcontinental mantle deformation, J. Geophys. Res. (in press).

Shimamura, H., T. Asada, K. Suehiro, T. Yamada and H. InATANI, 1983, Longshot experiments to study velocity anisotropy in the oceanic lithosphere of the northwestern Pacific, Phys. Earth Planet. Inte- 
riors, 31, 348-362.

Stephen, R. A., 1985, Seismic anisotropy in the upper oceanic crust, J. Geophys. Res., 90, 11383-11396.

高橋 学・木下重教・西澤 修・小出 仁・千葉 洋, 1984, 真三軸圧縮下でのウェスタリ一花崗岩の弾性 波速度異方性について, 地震 $2,37,67-79$.

Tanimoto, T. and D. L. Anderson, 1984, Mapping convection in the mantle, Geophys. Res. Lett., 84, $287-290$.

竹下 徹・唐戸俊一郎, 1989, 岩石の塑性流動によって 形成された地球内部の異方性, 地震 2, 42, 255-269.

坪井誠太郎, 1959, 偏光顕微鏡, 岩波書店.

Vinnik, L. P., V. Farra and B. Romanowicz, 1989a, Azimuthal anisotropy in the Earth from observations of SKS at GEOSCOPE and NARS broadband stations, 1989, Bull. Seism. Soc. Am., 79, 15421558.
Vinnik, L. P., R. Kind, G. L. Kosarev and L. I. MaKEYEVA, 1989b, Azimuthal anisotropy in the lithosphere from observations of long-period S-waves, Geophys. J. Int., 99, 549-559.

Woodhouse, J. H. and D. Giardini and X.-D. Li, 1986, Evidence for inner core anisotropy from free oscillations, Geophys. Res. Lett., 13, 1549-1552.

Young, R. P., S. TAlebi, D. A. Hutchins and T. I. URBABCIC, 1989, Analysis of mining-induced microseismic events at Strathocona Mine, Sudbury, Canada, PAGEOPH, 129, 455-474.

Yegorkina, G. V., V. A. Rakitov, I. V. Garetovskaya and L. M. YEGOROVA, 1977, Anisotropy of velocities of seismic waves and the stress state of the Earth's crust in the territory of Armenia, Izvestiya, 13, 554-562. 